\title{
Elements of practice in the analysis of auto-ethnographical cooking videos
}

\section{Torkkeli, Kaisa Leena}

2020-11-01

Torkkeli , K L , Mäkelä , M J \& Niva , M H 2020 , ' Elements of practice in the analysis of auto-ethnographical cooking videos ' , Journal of Consumer Culture , vol. 20 , no. 4 , pp. 543-562 . https://doi.org/10.1177/1469540518764248

http://hdl.handle.net/10138/321001

https://doi.org/10.1177/1469540518764248

acceptedVersion

Downloaded from Helda, University of Helsinki institutional repository.

This is an electronic reprint of the original article.

This reprint may differ from the original in pagination and typographic detail.

Please cite the original version. 


\title{
Elements of practice in the analysis of auto-ethnographical cooking videos
}

\author{
Kaisa Torkkeli, Johanna Mäkelä and Mari Niva \\ University of Helsinki
}

\begin{abstract}
This article analyses cooking videos recorded at home by means of the practice-theoretical approach. It employs two conceptualisations of the elements of practice that have stood out in recent applications of practice theories in sociological consumption and food studies. The first conceptualisation comprises understandings, procedures and engagements and the second materials, competences and meanings. To study cooking as a situationally performed mundane practice, auto-ethnographical videos of cooking were filmed using the first author's family. To analyse the practice of cooking as a composition of doings and sayings, the videos were coded with a video analysis programme, Interact, into visual charts, and the discussions related to cooking performances were transcribed. The analysis suggests that the cooking practice involves interplay among the elements of the two conceptualisations: procedures join materials with competences, engagements link competences with meanings and understandings connect meanings with materials. This is visualised as a triangle in which understandings, procedures and engagements represent the sides of the triangle between the apexes of materials, competences and meanings. By combining an auto-ethnographical perspective with a video method and by analysing the practice of cooking as a situational and embodied performance, the study contributes to the current understanding of the elements of practice and introduces a novel empirical application of practice theory.
\end{abstract}

\section{Keywords}

practice theory, elements of practice, video method, auto-ethnography, cooking

\section{Introduction}

This article explores how recently developed theories of social practices and their conceptualisations of the elements constituting practices are applicable in an analysis of cooking. In short, cooking can be defined as a bundle of tasks to prepare hot and cold meals (Mills et al., 2017). On the other hand, it can be thought of as part of foodwork, which involves all cooking-related practices, from meal planning, purchasing and serving to tidying up the kitchen (Meah, 2014; O'Connell and Brannen, 2016). In this article, we explore cooking as it occurs at home in time and space, facilitating an analysis of the practice of cooking as part of everyday, mundane life and as an embodied and situational practice.

Earlier studies on cooking have relied mostly on language-based methods, such as interviews (e.g. Bugge and Almås, 2006; Halkier, 2010; McCabe and De Waal Malefyt, 2015; Short, 2006; Wolfson et al., 2016). For instance, studies on cooking as foodwork have used interview data to analyse the gendered aspects of cooking (e.g. DeVault, 1991; Meah, 2014; Neuman, 2016). However, lately, the embodied forms of cooking have been explored using various methods, including photographing, videoing, interviewing and observing cooking performances (e.g. Meah and Watson, 2011; Sutton, 2006; Truninger, 2011).

To analyse not only the language acts of cooking but also to understand better the situational and embodied performance of cooking, we used auto-ethnographical video recordings of cooking. First, we were inspired by earlier studies that observed practices in kitchens through videos, providing an understanding of mundane practices as overlapping, intertwining and complex sets of performances (Martens and Scott, 2004, 2017; Wills et al., 2013). Second, the auto-ethnographical perspective enables 
the grasping of the "taken for granted" and "difficult to verbalise" dimensions of cooking (cf. Groth, 2017; Larsen, 2014; Shove et al., 2012: 99-100).

The video method provides rich, complex and unorganised audio-visual data whose analysis must be informed and guided by a relevant theory (Ash, 2007.) The theoretical basis of this study lies in social practice theories, which differ somewhat in their conceptualisations of what exactly "a practice" is but share an interest in "ordinary" life (Spaargaren et al., 2016). The present study is inspired particularly by the applications of practice theory in consumption and food studies of the past decades (e.g. Halkier, 2010; Shove et al., 2012; Warde, 2005, 2016). Previous research has applied various conceptualisations of the constituting elements of practices, differing in terms of their complexity and in the roles afforded to symbolic meanings, materialities and the ways in which the elements are defined. In this study, our aim is to examine whether and how two widely used conceptualisations can be used simultaneously. The first conceptualisation discerns understandings, procedures and engagements (Warde, 2005) and the second focuses on materials, competences and meanings (Shove et al., 2012).

By applying two differing conceptualisations and the six elements of practice together, the present study aims to analyse cooking subtly and theoretically rigorously. Thus, the main objective of this article is to contribute with empirical examples to the intelligibility of the elements of practice and to improve their use in empirical analysis. The study examines, on one hand, the ways in which the different elements are useful in analysing cooking performances and, on the other, whether and what kind of interplay can be discerned between the elements.

The combination of the auto-ethnographical perspective and the video method enables an analysis of the practice of cooking in a way that, to our knowledge, has not yet been tested in practice-theoretical research. Additionally, the video method facilitates an analysis of both doings and sayings carried out during cooking (Wills et al., 2016). This is crucial, because practice is "a nexus of doings and sayings" (Schatzki, 1996: 89); therefore, any analysis of practice must concern both (Warde, 2005: 134, 2016: 39).

In the following sections, the six conceptual elements of practice are discussed and applied in an analysis of auto-ethnographical videos of cooking in a Finnish family with children. We first take a close look at cooking as a practice and at the elements of practice as presented in various versions of practice theory. Thereafter, we explain our methodological decisions concerning the production and analysis of the auto-ethnographical video data. In the results section, we present our findings based on the analysis of doings and sayings in the videos. Finally, we bring together and synthesise the results in a graphical form, and we discuss critically our conceptualisation of the cooking practice.

\section{Practice of cooking}

A characteristic of social practices is their dual nature as carried out performances and socially coordinated entities. The existence of practice as an entity makes it possible to envisage and recognise the cooking practice based on a collective memory or informal consensus about what activities (sayings and doings) are required to carry it out (e.g. Warde, 2016). Cookbooks and recipes are representations of such practices as entities designed to transmit the codified knowledge and principles of cooking (Warde, 2016: 48-49, 84). However, cooking is sustained over time only through the moments in which people continue to carry out cooking and reproduce linkages between the diverse elements of which the practice is composed (Shove et al., 2012: 6; Warde, 2005). Therefore, understanding, competence and know-how are not merely personal features, but also elements and properties of social practice. From this perspective, people pursue a given social practice as active "carriers" (Reckwitz, 2002: 250) or "hosts of a practice" (Shove et al., 2012: 7).

Consequently, a socially coordinated practice can be carried out slightly differently on diverse occasions, depending on the temporal and spatial circumstances. For instance, cooking a pizza is a 
practice globally recognised as an entity. However, situational circumstances, such as when, where, for whom and from what ingredients the pizza is cooked, affect how the particular performance is carried out. The enormous number of pizza recipes and the internal variety of performances increase the complexity of this socially coordinated practice (Warde, 2016: 43). The differently performed practices spark continuing changes that are not dependent only on individual agents (e.g. Shove et al., 2012; Warde, 2005). Rather, practice theory removes the focus from individual cognitions and thus does not overrate the rationality of practitioners (Keller et al., 2016), who tend to repeat everyday routines.

Social practices are fundamentally based on routines and reproduction (Reckwitz, 2002). For example, cooking can rest on such routines as bodily movements (peeling), using and understanding materials (perceiving a carrot as edible) and wanting (familiar ingredients) (Reckwitz, 2002: 255). These different types of routines are regularly repeated steps that interconnect and form the flow of the routinized practices of mundane cooking. Repetitive routines make everyday life easier (Warde, 2016: 127), whereas a departure from routines typically occurs during everyday crises involving confronting and overcoming situational problems (Reckwitz, 2002: 155).

Such situational problems are an essential part of life in families with children (O'Connell and Brannen, 2014). Families live their everyday lives within a field of social practices (Schatzki, 2001b: 10) comprising a tangled diversity of parenting-, transporting- and food-related practices (Halkier, 2010: 2628). This requires continual planning, scheduling and debating how to manoeuvre the family in the midst of overlapping practices. Therefore, everyday cooking should also be understood as a flexible and situational process of constantly evaluated and negotiated performances (Halkier, 2009) that are not directly comparable to representations of cooking as socially shared entities (Martens and Scott, 2017). The continual actions that people carry out create complex networks of doings and sayings that affect one another but that become linked by the particular elements that organise recognisable practices (Schatzki, 1996: 103).

\section{Elements of practice}

To understand a practice, scholars have defined and applied diverse conceptualisations of the elements constituting or organising practices (see Gram-Hanssen, 2010; Spaargaren et al., 2016). Likely, the most cited and exhaustive definition is that of Reckwitz (2002: 249), who defines practice as "a routinized type of behaviour" that consists of "forms of bodily activities, forms of mental activities, 'things' and their use, a background knowledge in the form of understanding, know-how, states of emotion and motivational knowledge". Schatzki (1996, 2001a, 2016) defines practices as being organised by common understandings, rules and teleo-affective structures.

However, recent works on practice theories highlight, in particular, two more concise conceptualisations of the elements of practice that have been simpler to apply in empirical work than the definitions above (e.g. Spaargaren et al., 2016; Welch and Warde, 2017: 183). Both conceptualisations (Warde, 2005; Shove et al., 2012) are still based on Reckwitz's (2002) and Schatzki's (1996) definitions. Warde (2005: 134) develops Schatzki's concepts for analytical purposes, referring to them as "understandings, procedures and engagements". Because many empirical studies have demonstrated the fruitfulness of these concepts (e.g. Halkier, 2010; Jauho et al., 2016; Warde, 2016), we utilise them, abbreviating "understandings, procedures and engagements" to UPE for ease of reference. Shove et al. (2012: 10) argue for a "suitably materialised" theory to improve the usefulness of the elements in analysing the permanence and conversions of practices. Because cooking is indeed a practice involving various kinds of materials, the second conceptualisation of the elements useful for our purposes is the triangle of "material, competence and meaning" by Shove et al. (2012), which we abbreviate to MCM. 
The most remarkable difference between UPE and MCM relates to the notion of materials as an element of practice. According to Schatzki (2010; 2016), materials are not a part of elements. Instead, the material arrangements of bodies, tools and ingredients, together with multiple practices, form practice-arrangement bundles (Schatzki, 2016). For Schatzki, practices can generate material arrangements, but materials are conceptually distinct from practices. This is why in contrast to MCM, UPE does not refer to materials.

Shove et al. (2012) developed their conceptualisation to account for trajectories of practices and targets for possible interventions. They suggest the conceptualisation of practices, materials and practitioners may be more understandable if the materials are considered an element of practice (Shove et al., 2012: 10). Thus, they refer to Reckwitz (2002: 249, 252), who includes "things" and "objects as necessary components of many practices". Shove et al. (2012: 14, 24-29) define materials as "objects, infrastructures, tools, hardware and the body itself"; competence as "skill, know-how and technique"; and meaning as "social and symbolic significance" linked to the practice. In addition, they picture the elements (MCM) as corners of a triangle, emphasising that when a practice exists, the elements integrate and form interdependent relations between each other.

The concepts of UPE are built on the notion that practices are sets of doings and sayings governed by a group of elements (understandings, procedures, engagements) and linked together to constitute a socially recognisable practice (Schatzki, 2016; Warde, 2016). Following Schatzki (1996, 2001a) and Warde (2005), scholars have defined the elements (of UPE) as follows. Understandings are knowledge in a broad sense, "articulated in the 'sayings' of various practices" (Schatzki, 2017; Welch and Warde, 2017: 194). Procedures are principles, rules and tacit knowledge for how to do something, although a competent practitioner may be unable to articulate these rules (Warde, 2016: 39-40). Engagement refers to purposes, motivations or emotions surrounding what, why and "how to do" (Halkier, 2010: 29), which may become verbalised in discussions of "what is important to me" and why (Martens, 2012: 5.1). Schatzki (1996: 101) refers to engagements as teleo-affectivities that contain "desires, hopes and wants" about "ends and purposes" that can be treated as normative and accepted conducts linked to the practice.

Despite the analytical separation of the elements at a conceptual level, practice theorists acknowledge they are mutually interdependent, as the components affect and depend on one another. As Schatzki (2001a: 59-60) describes, we do what makes sense to us, revealing our understandings of both the practice in general and the rules and procedures in particular. However, rules related to practices determine what we do only occasionally (Schatzki, 2001b: 60). For instance, we may have knowledge of nutrition recommendations and an understanding of appropriate procedures to follow those, but the practice of cooking can still be carried out according to other principles, such as avoiding food waste. Thus, the performance manifests the engagements of the practice. Consequently, the practice, as a socially constructed organisation, contains social norms the practitioner negotiates and acts out depending on temporal and spatial circumstances (Halkier, 2010: 37).

A summary of the basic definitions of the elements of UPE and MCM is presented in Table 1, revealing both shared features and significant differences. For example, the concepts of procedures and competence refer to know-how, but they differ in their relation to power. The procedures, referring to rules and principles, can be thought of as "means of exercising power" whereas the concepts of MCM hardly refer to power (Watson, 2017: 172). Conversely, Shove et al. (2012: 23) unite "multiple forms of understandings" with competences. A comparison between meaning and engagements shows that while meaning refers to social or symbolic significance in a general sense, engagements point to the temporal and emotional characteristics of purposes, ends and hopes (Shove et al., 2012: 24). The comparison suggests the elements of UPE are not as distinct as those of MCM. However, our results show the concepts become more intelligible when applied simultaneously in analysing the videos. 
Table 1. Elements of Practice

\begin{tabular}{|l|l|l|}
\hline $\begin{array}{l}\text { Conceptualisations } \\
\text { of elements }\end{array}$ & Element & Definition \\
\hline \multirow{3}{*}{ UPE } & Understandings & Knowledge represented as text and talk \\
\cline { 2 - 3 } & Procedures & Rules, principles, know-how \\
\cline { 2 - 3 } & Engagements & Emotional and normative orientations, motivations \\
\hline \multirow{2}{*}{ MCM } & Materials & Bodies, things, tools, objects, infrastructure \\
\cline { 2 - 3 } & Competences & Skills, know-how and techniques \\
\cline { 2 - 3 } & Meanings & Social and symbolic significances \\
\hline
\end{tabular}

\section{Auto-ethnographical cooking videos}

The data of this study are auto-ethnographical cooking videos. Visual methods, such as videoing, have been utilised in studies of cooking skills together with observation (e.g. Meah and Watson, 2011; Sutton, 2006; Truninger, 2011), but most cooking studies rely mainly on language-based methods, such as interviews (e.g. Bugge and Almås, 2006; Halkier, 2010; McCabe and De Waal Malefyt, 2015; Short, 2006; Wolfson et al., 2016). Talking about cooking may stimulate participants to discuss primarily the meanings and motivations related to the practice (Martens, 2012), but the video method also records the situational and embodied aspects of cooking that may be difficult to recall or verbalise (Martens and Scott, 2017; Pink, 2012a, 2012b; Wills et al., 2016). We used the video method to obtain a picture of mundane cooking as comprehensively as possible.

Auto-ethnographical studies have been interested in forms of embodied routines and tacit knowledge (e.g. Brady, 2011; Groth, 2017; Larsen, 2014). By watching and making field notes about one's own performance, the researcher may be able to identify her/his embodied and normative routines and recall the motives, emotions and tacit knowledge related to the recorded cooking sessions. However, this perspective provides an opportunity not only to be more aware of the researcher's own perceptions and routines, but also to explore multiple (e.g. mental, non-verbal, embodied, normative, motivational) aspects of social life in greater depth (Anderson and Austin, 2012: 141). The video data of this study illustrate the mundane practice of cooking, while the first author and her family represent the carriers of the social practice. This directs and reminds the researcher to consider also the other practice carriers' interpretations, sensations or ideas, as well as her own (Anderson, 2006: 389).

The first author collected and analysed the data. The participants in this study were her and her family (husband, daughter aged 10 and son aged 6). The data comprised six video-recorded cooking sessions from two periods. Dinner cooking was chosen as the subject of the video recordings, because dinner remains the primary and most complex meal prepared at home in Finland (Holm et al., 2012; Mäkelä, 2009). Following Lahlou's $(2011,2015)$ Subjective Evidence Based Ethnography (SEBE) approach, the videos were recorded with a wearable video camera fixed to the temple at eye level. The camera recorded vertical and 160-degree videos from the user's perspective, allowing both the hands and surrounding environment to be seen throughout cooking.

The first data collection period started on 30 November and ended on 10 December 2015. During this period, the first author video-recorded four meal-cooking sessions. The second data collection period took place between 28 April and 1 May 2016, and it included two recorded meal-cooking sessions. In 
one of these, the husband wore the camera. ${ }^{1}$ The recorded cooking sessions lasted from 30 to 40 minutes, except in the case of one session (pizza), which took 69 minutes. $^{2}$ Each video began when ingredients were brought to a table and ended when the heat of the oven or stove was turned off or the camera user felt the cooking was done.

All six video-recorded sessions were analysed to ensure the analytical frame worked consistently for the whole data set. For a closer examination, we chose videos that represented a variety of doings and sayings, the intensity of which tended to vary according to the presence or non-presence of other family members in the cooking sessions. Table 2 presents the two videos chosen for a detailed analysis.

Table 2. Two Cooking Videos Depicting Cooking Performances

\begin{tabular}{|l|l|l|l|l|l|}
\hline Cooked dish & Day & $\begin{array}{l}\text { Duration of } \\
\text { recording }\end{array}$ & $\begin{array}{l}\text { Who wore } \\
\text { the } \\
\text { camera? }\end{array}$ & $\begin{array}{l}\text { Who is helping } \\
\text { to cook? }\end{array}$ & $\begin{array}{l}\text { Who else } \\
\text { attended? }\end{array}$ \\
\hline Sausage soup & $\begin{array}{l}\text { Thursday } \\
\text { 3 Dec } 2015\end{array}$ & $30 \mathrm{~min}$ & $\begin{array}{l}\text { first author, } \\
\text { (Kaisa) }\end{array}$ & & daughter \\
\hline Pizza & Friday & $1 / 330 \mathrm{~min}$, & $\begin{array}{l}\text { first author, } \\
\text { (Kaisa) }\end{array}$ & husband & daughter and son \\
& 4 Dec 2015 & $\begin{array}{l}2 / 330 \mathrm{~min}, \\
3 / 39 \mathrm{~min}\end{array}$ & & \\
\hline
\end{tabular}

\section{Practice theory-based analysis of video data}

The analysis consisted of three stages (Ash, 2007). At the first stage, the video data were explored to develop a coding scheme. At the second and third stages, the definition of practice as a nexus of doings and sayings (Schatzki 1996) was put into operation. The second stage of the analysis focused on the doings in the videos, while the third concentrated on the sayings.

In the beginning, the analysis relied on the notion that recipes are codified entities of the practice of cooking (Warde, 2016). The general structure of recipes was categorised into four pre-defined classes that were used in coding the activities of cooking: prepare, combine, heat up and seek information. When developing the coding scheme, the recipe-focused classes were further divided into 10 codes that depicted different strategies of cooking, from heating up microwavable food to cooking from scratch.

The coding relied on the concepts of MCM, because the materiality of the practice was evident in the footage. An exploration of how the materials were handled in the videos revealed the intertwining of competences (select, peel, form) and materials (ingredients, tools, hands). This led to creating new codes, such as "select ingredients and tools" and "form with a tool or by hand" (Table 3). Such codes could also be interpreted as procedures based on cultural rules relating to the practice.

The relationship between materials and competence was evident and active in the cooking codes related to the classes of preparing, combining and seeking knowledge. The codes of the class "heat up" however, differ from each other in terms of materiality. The code "regulate temperature", as an active handling of material, refers to controlling heating as a competent doing, while the codes "on a stove" and "in an oven" could appear without any active handling of materials. Thus, heat appears as a nonmaterial and nonverbal but active participant of the practice that changes the ingredients of cooking in essential ways.

\footnotetext{
${ }^{1}$ In Finland, women cook for approximately 47 minutes per day, which is more than twice that of men (Pääkkönen and Hanifi, 2011: 28).

${ }^{2}$ This session comprises three documents, because the camera saved the recordings as three separate but seamlessly sequential 30-minute pieces.
} 
As cooking is a part of foodwork entangled in everyday life (O'Connell and Brannen, 2016) ${ }^{3}$, the coding scheme incorporated the occurrences related to tidying up, finalising and talking, as these were also integral parts of the goings-on in the videos. Each of these three classes were divided further into two codes representing various occurrences relating to the class (Table 3).

\begin{tabular}{|l|l|}
\hline \multicolumn{2}{|l}{ Table 3. Coding Scheme for Cooking Videos } \\
\hline Classes & Codes \\
\hline Prepare & Select ingredients and tools \\
\cline { 2 - 2 } & Remove inedible parts of ingredients \\
\cline { 2 - 2 } & Form with a tool or by hand \\
\hline \multirow{4}{*}{ Combine } & Add \\
\cline { 2 - 2 } & Stir, turn \\
\hline \multirow{3}{*}{ Heat up } & Regulate temperature \\
\cline { 2 - 2 } & On a stove \\
\cline { 2 - 2 } & In an oven (inc. microwave) \\
\hline \multirow{3}{*}{ Seek knowledge } & Taste, touch (embodied) \\
\cline { 2 - 2 } & Read, look at \\
\hline Tidy-up & Rearrange \\
\cline { 2 - 2 } & Wipe surfaces or wash tools and hands \\
\hline Finalise & Finish for serving \\
\cline { 2 - 2 } & Set a table \\
\hline Talk & About food \\
\cline { 2 - 2 } & About other issues \\
\hline
\end{tabular}

The second stage of the analysis comprised coding the six cooking videos according to the scheme presented in Table 3 with the video analysis programme, Interact (Groth, 2017). The programme can be used to visualise the enactments and the time allocated to each in a linear form. Although the coding cannot grasp easily all the occurrences and nuances that appear in the videos, it facilitates the analysis of the routinized doings. As a result, the development of the coding and analysis of doings together identified three elements of practice: material and competence, which are MCM-based concepts, and procedures, which originates from the UPE conceptualisation.

To manage the complexity of occurrences (Ash, 2007: 209-210), the coding of activities was carried out from the perspective of only the person wearing the camera, even when the cooking was performed together with other family members. This meant that all the minute details of the cooking process were coded only in cases when the practitioner was cooking alone. When other family members participated in the cooking, their actions were recorded on the videos but not coded, except their discussions. The sayings of the cooking performances were transcribed while coding the visual recordings.

The sayings of practice constituted the data for the third stage of the analysis by exploring them as texts and voices, but also in relation to the doings. The code "talk about food" proved essential for understanding the continual negotiation and situational matters of cooking. These sayings elicited the meanings of cooking (Martens, 2012), representing the third element of MCM. Food-related sayings comprised discussions, negotiations and debates about the division of tasks, personal food preferences

\footnotetext{
${ }^{3}$ For example, in the pizza video, for the first 25 minutes, Kaisa was making pizza dough in a mixer and simultaneously talking with her husband about their jobs and schedules or just staring at the mixer lost in thought. The example showed that during a performance, multiple activities, some of which are unrelated to the practice of cooking, take place (Martens and Scott, 2017).
} 
and differing ideas or expectations relating to a particular cooking situation. We noticed that in many cases, 'talk about food' could be interpreted as verbalisations of understandings or engagements (Warde, 2005: 134). Because sayings conveyed general knowledge about materials, such as negotiations about acceptable tools and ingredients, they were linked to the cooking performance by understandings. Such participation in the practice, through sayings, was possible, even without engaging in the actual cooking performance. In other cases, the 'talk about food' concerned motivations, normative conducts and emotionally justified purposes related to doings. These were interpreted as engagements. It was thus evident that understandings and engagements, which are constitutive elements in UPE, could be discerned in the sayings.

\section{Results}

\section{Unpacking doings: Procedures, materials and competences}

For the first author as a practitioner, everyday cooking mostly means routinized doings. Especially while cooking alone, it is a process, a flow of occurrences and a task-feeding work - that a parent simply must do (DeVault, 1991). However, the visual data facilitated a step back from the visceral routines of cooking as she watched her own doings as an outsider. This allowed for an examination of doings as examples of cooking performances from the analytical and reflexive perspective of a researcher. The recorded and coded performances revealed the structure of routinized cooking and shed new light on the complex nexus of doings.

From the auto-ethnographical perspective, cooking performances were continuous but routinely evaluated, and embodied interactions between the practitioner and the material environment were based on repetition and ease. In the case of cooking "sausage soup", depicted by the process chart in Figure 1, cooking was guided especially by the materials at hand and by a mental idea of some sort of soup, but not specified by a certain recipe. The successive and occasionally overlapping doings revealed the takenfor-granted procedures constructing a cooking process. Figure 1 illustrates, among other things, how talking with the daughter did not interrupt the doings of cooking, how the cooking was repeatedly evaluated by testing or tasting (code "seek knowl. test, taste") and how the practitioner often watched the clock (code "seek knowl. read, look"). Additionally, Figure 1 illustrates how the doings, particularly relating to the codes "form, e.g. cut" (the third row) and "add" (the fourth row), were prompted by changes in the materials at hand.

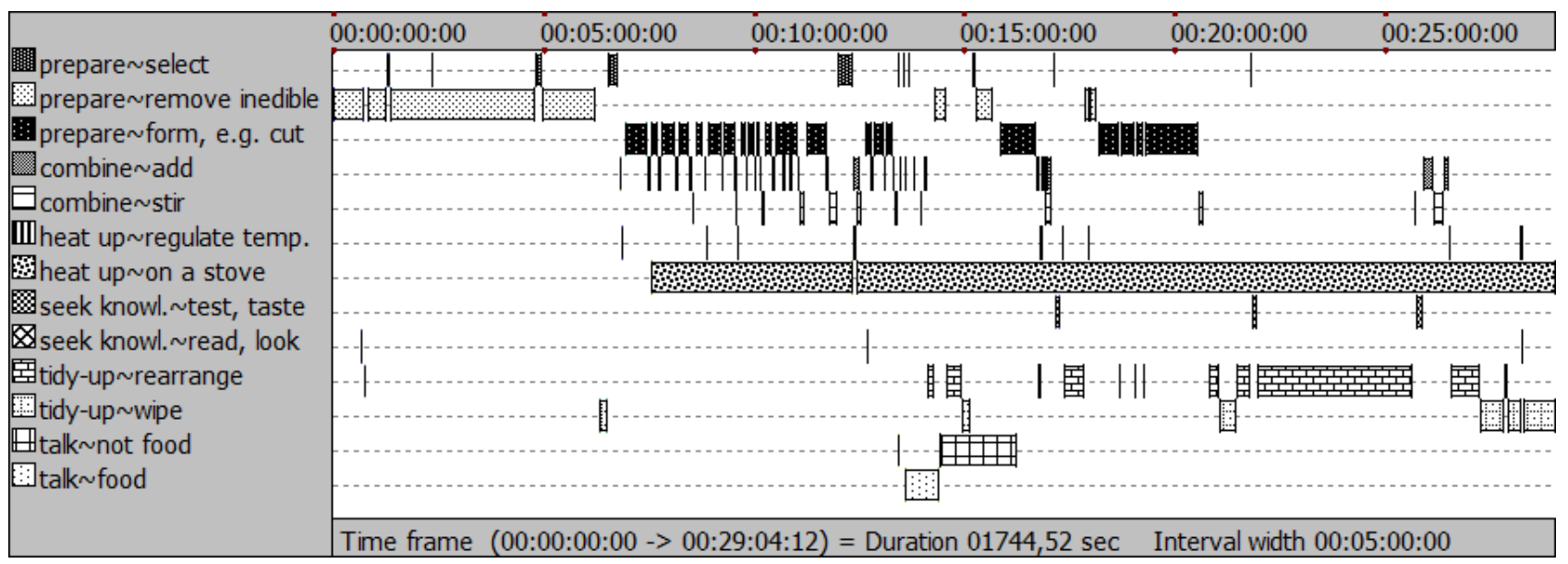

Figure 1. Process of cooking 'sausage soup' 
The primary point of departure for the coding of doings was the general structure of a recipe as codified knowledge of cooking. During the analysis, the structure of cooking was found to be a fragmented rather than regular process. Although this could be considered obvious, it is important to ask what causes such fragmentation, even if a practitioner is cooking alone and feels like carrying out easy routines. For example, preparing vegetables for a soup could be expressed in a recipe passage as "cut the vegetables and add them into the pot". However, in the "sausage soup" video, the cooking stage was carried out as a repeated series of doings_ - "cut, add, cut, add, cut, add..." - that appears as a fragmented structure in the process chart (Figure 1). This fragmented performance was due to a small cutting board, which forced the first author as the cook to move the chopped vegetables in small lots to the pot. Nevertheless, for her, the solution still felt like a routinized doing, and she did not feel forced to change the cooking procedure or to use a larger cutting board. Instead, the performance revealed the practitioner's competence in cutting the vegetables into different sizes, depending on their cooking times, and adding them to the pot in the optimal order. An awareness of available materials (i.e. tools and ingredients) and several tacit and embodied competences applied to these materials guided the process smoothly forward.

Thus, the recipe's customary advice to "cut the vegetables and add them into the pot" can be interpreted as representing a socially constructed rule or principle of the practice (cooking a soup) as an entity. However, as revealed by the monitoring of the practice of cooking the soup, in performance, the practice occurs as the competent utilisation of available materials and does not necessarily follow the entity-level description. Thus, the recorded videos facilitated a better understanding of the link between cooking-related materials and competences that express situated cooking procedures. In other words, routinized procedures following the general principles of cooking the soup direct the use of available materials and embodied competences.

\section{Unpacking sayings: Meanings, understandings and engagements}

The most useful route for exploring tacit knowledge of cooking proved to be video-recorded situations in which the first author (Kaisa) and her family were cooking together. They discussed their thoughts about the food in hand and consulted one another about ingredients and their preparation. These negotiations revealed the situational meanings of cooking that elicited general understandings, motivations and purposes related to a particular performance. The complexity of cooking in a family with children is illustrated in the transcribed discussion below, which occurred when all family members were in the kitchen. Kaisa felt tired and tried to get off easy by making only one "minced meat pan pizza" instead of individual pizzas for everyone, as they usually would. The discussion shows differing understandings of the practice among the family members. The transcription is from the highlighted (a vertical light grey) episode in the process chart in Figure 2.

Transcribed conversation (time frame 00:08:20:05 $\Rightarrow>00: 09: 31: 16$ )

Son: $\quad$ Oh yes! May I!? (He sees a roller and would like to roll, as he usually does when they make individual pizzas for everyone.)

Kaisa: $\quad$ No, this is mum's job right now. Here is just this one (dough ball).

Husband: $\quad$ Should there be the tomato sauce on the bottom as well? (Earlier in the footage, Kaisa asked him to add the tomato sauce to the fried minced meat.)

Kaisa: $\quad$ No, let's make it this way for now. It's going to be like this now. This is this kind of everyday pizza. Now don't even... (She would like to avoid any complaints.)

Husband: Are there going to be pineapples? 
Kaisa: $\quad$ I don't know; it depends on you. (She sounds a bit nervous, since she knows that such a pan pizza will test the boundaries of convention.)

Son: $\quad$ Yes, pineapples!

Kaisa: $\quad$ To this, to this (she raises her voice so that everyone will listen). Please, listen! This is an everyday pizza; this has no connection to the pizzeria's pizzas or to our gourmet pizzas. This is this kind of ordinary everyday hodgepodge.

Husband: Everyday hodgepodge. Fast action. We don't have any pineapples. Is tinned pea soup ok? (He is rummaging a cupboard.)

Kids together: Noooo!

Kaisa: $\quad$ Let's add minced meat and cheese.

Son: $\quad$ Just minced meat and cheese!?

Kaisa: $\quad$ Yup.

Son: $\quad$ And blue cheese?

Daughter: Why blue cheese?

Kaisa: $\quad$ Well, no need to add it everywhere.

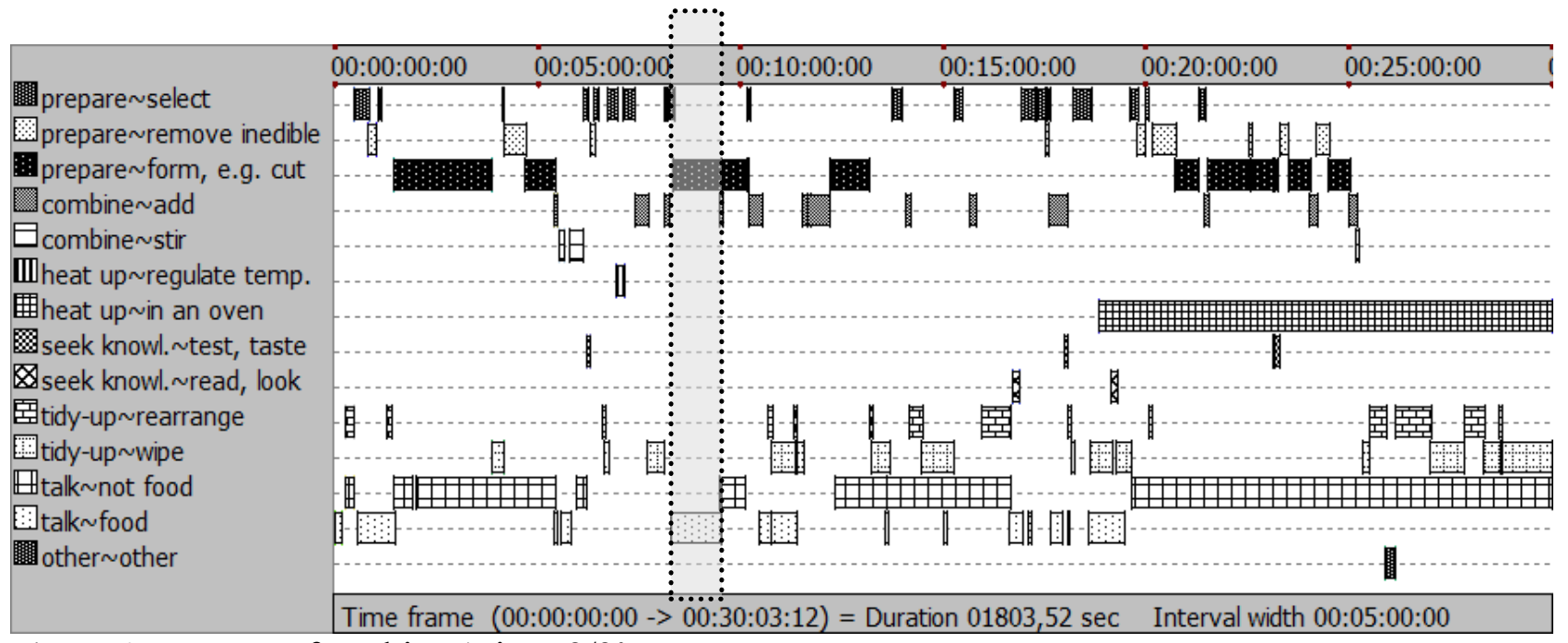

Figure 2. Process of cooking 'Pizza 2/3'

The understanding of pizza was negotiated in sayings during the performance. Former experiences with the dish directed the family members' understandings of appropriate pizza toppings. Therefore, the pizza, made with a slightly different procedure than their usual pizzas, caused uncertainty about suitable toppings as materials in this particular performance. Limits of suitable materials were defined by the husband's joke (pea soup has no meaning in relation the pizza). Thus, the negotiation revealed a link between materials (pizza toppings) and meanings (familiar pizza traditions), and that linkage can be expressed as understandings (of suitable materials) that play a role in organising the situational practice of cooking a pizza. In other words, understandings indicate how materials attain meanings and how meanings were shaped by materials.

In the previous example of performance, Kaisa had a mental plan for the cooking process: to use the aging meat and to feed the family easily using food that everyone will eat. When analysing the video, she was able to recall the preliminary aims while observing her doings and the family's video-recorded conversation. The pizza in her mind was based on her childhood experiences and a picture of pan pizza she had recently seen, meaning familiarity and ease (compared to "gourmet pizzas"). Overall, the aim of the performance was to simplify the cooking by following her plan. Thus, she took the main responsibility of carrying out the plan, and in consequence, her competences primarily defined how the performance 
was enacted. She had the competence, a capability to cook the pizza that carries the meanings of ease and familiarity. By cooking a pan pizza, the competences and the meanings linked together and revealed what was important to her and worthy of doing. Thus, the link between competences as embodied doings and meanings as a mental plan was manifested in the engagements. In other words, engagements as performed pointed out what plans and aims, representing socially shared meanings, were worthy of performing in the particular situation.

\section{Discussion}

The results of this study show that all six elements of practice are applicable in an analysis of cooking practice. The essence of the MCM and UPE conceptualisations is that their elements coordinate a practice. However, the interplay between the conceptualisations was unclear until the empirical analysis of the cooking videos revealed the nature of the links between the elements of MCM (material, competence and meaning). Shove et al. (2012) expressed the "interdependent relations between elements" as a triangle in which the apexes represent the elements and the sides represent the links between them (Shove et al., 2012: 24). We brought forth the links between the elements of MCM with empirical examples, and we suggested that the elements of UPE might represent those links. The analysis of the interplay between the two conceptualisations makes the six concepts more comprehensible, and it facilitates a more subtle and systematic interpretation of a practice.

Based on our findings, we suggest that the sides of the triangle can be named according to the elements of UPE (understanding, procedures and engagement). The sides of the triangle in Figure 3 depict the interplay of the two conceptualisations of the elements as follows: (1) the link between materials and competences can be conceptualised as procedures, (2) the link between meanings and materials as understandings and (3) the link between meanings and competences as engagements. In addition, the curved line inside the triangle shows how the links became discernible as the analysis focused on either doings or sayings. The analysis of doings utilised materials, competences and procedures, while the analysis of sayings concentrated on meanings, understandings and engagements.

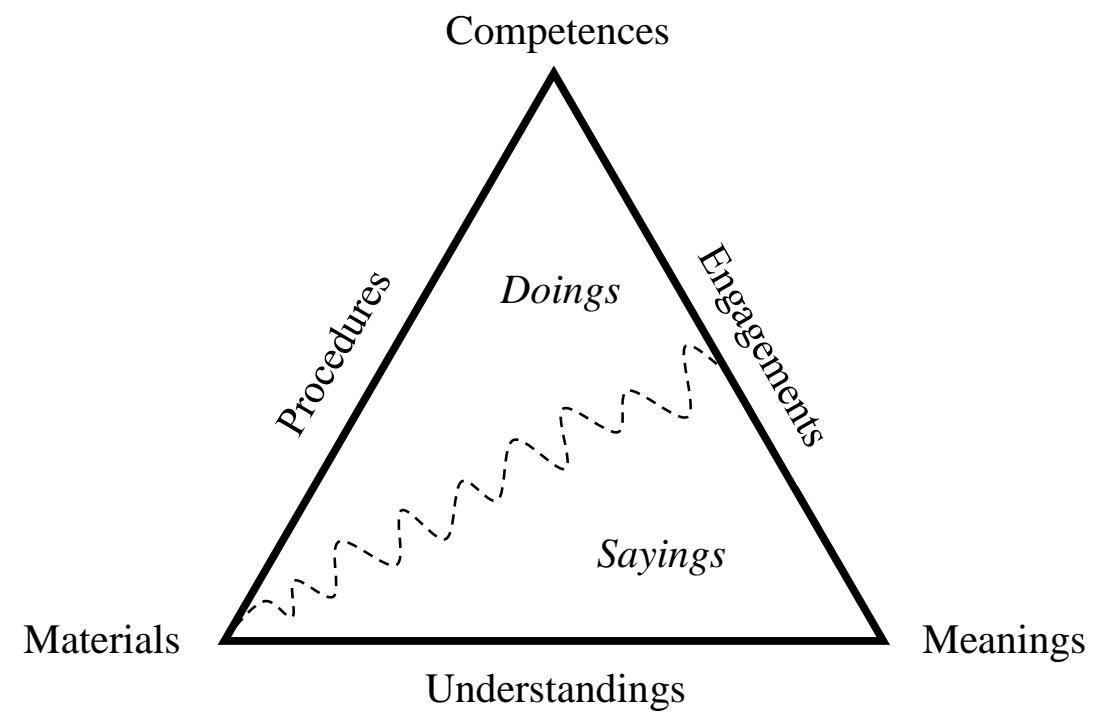

Figure 3. The triangle of elements of practice and their manifestations as doings and sayings in cooking 
In Figure 3, the procedures side indicates a link between materials and competences. Procedures as rules and principles unfolded in the analysis, when the practitioner applied the materials of cooking in a competent manner. Thus, the doings of cooking were performed according to socially approved rules and principles, which mandate, for example, that carrots should be peeled and diced into the soup. The carrying out of procedures as rules and principles also involves understandings about materials and their relations to historically and socially specified meanings (Reckwitz, 2002: 253; Schatzki, 2001b: 3). In this context, the family negotiated the appropriate pizza toppings, which represented understandings. The side of the triangle labelled as understandings represents the link between materials (pizza toppings) and meanings (familiar pizza traditions). In other words, understanding "presents a way to explicate the role of culture in practice" (Welch and Warde, 2017: 195).

As was expected, the meanings of cooking were revealed through the analytical focus on sayings linked to the practice (Martens, 2012). Although the embodied and sensory knowledge engaged in performances cannot always be verbalised (Martens et al., 2014, Martens and Scott, 2017), the autoethnographical perspective of the first author made it possible to integrate unspoken representations and reflections into the analysis. Watching the videos reminded Kaisa of a whole repertoire of motives and emotions that affect the performances as plans and aims (e.g., cooking a pan pizza) that again represent meanings of cooking (familiarity and ease). In the situational performance, she applied her competences when implementing the plan. Simultaneously, she displayed her engagements by carrying out the plan that was the most feasible in that situation. Thus, the third side of the triangle, engagements, indicates a link between competences and meanings, and it reveals which situational possibilities are experienced as worthy of performance (Warde, 2016: 146-147). This suggests it is fruitful to analyse engagements as both the implemented doings of cooking and by recalled and verbalised situational aims and plans.

Shove et al. (2012: 11) did not develop their model (MCM) for studying "situated practices" in particular, but the trajectories of practices. Thus, in light of this study, elements of MCM can be seen as forming the resilient possibilities of cooking practice. The elements of UPE again organise sets of doings and sayings (Schatzki, 1996; Warde, 2005), which were analysed in this study as occurrences of situational performances. Therefore, the analysis interpreted procedures, understandings and engagements as more situational elements of cooking than the elements of MCM.

Overall, our interpretation of the elements and links between them is based on the differences of the theoretical concepts. Albeit, the elements are mixed together, and they affect each other in performances of practice. The theoretical concepts as the means of analysis may result in quite rigid conceptualisations of practices if the situational aspects of practice are not considered in the analysis (Martens and Scott, 2017). However, we hope the analysis above has shown that the utilisation of all six elements together can improve the practice-theoretical discussion of mundane practices and bring new approaches for empirical analyses.

\section{Conclusion}

This study has addressed the elements of practice as theoretical concepts and analytical tools in the analysis of cooking videos. The combination of the video method and the auto-ethnographical perspective was crucial to utilise simultaneously the elements from two divergent conceptualisations: understanding, procedures, engagements (UPE), and materials, competences, meanings (MCM). The video recording focused the view exclusively on the cooking performances, producing detailed data of performed doings and sayings and inviting a practice theory-based analysis (Warde, 2016: 39).

The auto-ethnographical view facilitated a consideration of the embodied and tacit knowledge that was a key factor in detecting the non-verbal forms of elements. Especially, engagements unfolded for the participant-informant-researcher (Kaisa) as encounters among sayings, doings and non-verbal 
feelings related to those activities. For example, cooking a pizza was performed together with family members by negotiating, but leaning mainly on Kaisa's competences and mental plans, with which a sense of duty (of feeding) and a tired mood were mixed. This points to the impact of emotions as the practice is performed; however, from the point of practice theory, the emotions are not the property of the practitioner but of the social practice (e.g. Weenink and Spaargaren, 2016). The view of practitioners as carriers of social practices fits in with Anderson and Austin's (2012: 140) idea about auto-ethnography as a method that "provides a valuable and often unique window through which to observe social life". Thus, the auto-ethnographical perspective was not for self-reflection, but for understanding the social context in which we live. The perspective demands an assiduous consideration of other practice carriers' (such as family members) situational interpretations and approaches, as well. This raises again the question of how informants' mental plans, emotions or other situational engagements can be studied from outside by interviewing.

As our interpretation of elements stems from previous conceptualisations of elements (Shove et al., 2012; Warde, 2005), it will be interesting to see how applicable it is to analysing practices other than cooking. The use of six elements of practice rather than three may facilitate a better scholarly understanding of the organisation of practices. Our elucidation of the relations between the elements suggests avenues for further research: for instance, how does competence affect engagements or how do socially shared meanings become situational engagements? These questions are particularly interesting from the perspective of learning, for example, more sustainable or wholesome practices.

This study did not consider the practice-arrangement bundles (Schatzki, 2016) that are intermingled with each other. To improve the understanding of larger phenomena, such as families' foodwork, the entangled bundles of practices must be considered. Thus, this study will be expanded through analyses of cooking among several families with children, in which the overlapping and parallel practices of family life are observed to clarify their influences on foodwork. 


\section{References}

Anderson L (2006) Analytic autoethnography. Journal of Contemporary Ethnography 35(4): 373-395.

Anderson L and Austin M (2012) Auto-ethnography in leisure studies. Leisure Studies 31(2): 131-146.

Ash D (2007) Using video data to capture discontinuous science meaning making in nonschool settings. In:

Goldman R (ed) Video Research in the Learning Sciences. Mahwah, N.J: Lawrence Erlbaum Associates, Inc, pp.207-226.

Brady J (2011) Cooking as inquiry: A method to stir up prevailing ways of knowing food, body, and identity. International Journal of Qualitative Methods 10(4): 321-334.

Bugge A and Almås R (2006) Domestic dinner: Representations and practices of a proper meal among young suburban mothers. Journal of Consumer Culture 6(2): 203-228.

DeVault ML (1991) Feeding the Family: The Social Organization of Caring as Gendered Work. Chicago: The University of Chicago Press.

Gram-Hanssen K (2010) Standby consumption in households analyzed with a practice theory approach. Journal of Industrial Ecology 14(1): 150-165.

Groth C (2017) Making Sense through Hands: Design and Craft Practice Analysed as Embodied Cognition. Aalto University, School of Arts, Design and Architecture: Helsinki.

Halkier B (2009) Suitable cooking? Food, Culture \& Society 12(3): 357-377.

Halkier B, Katz-Gerro T and Martens L (2011) Applying practice theory to the study of consumption: Theoretical and methodological considerations. Journal of Consumer Culture 11(1): 3-13.

Halkier B (2010) Consumption Challenged: Food in Medialised Everyday Lives. Farnham: Ashgate.

Halkier B and Jensen I (2011) Methodological challenges in using practice theory in consumption research.

Examples from a study on handling nutritional contestations of food consumption. Journal of Consumer Culture 11(1): 101-123.

Holm L, Pipping Ekström M, Gronow J, Kjærnes U, Bøker Lund T, Mäkelä J, et al. (2012) The modernisation of Nordic Eating. Styling changes and stabilities in eating patterns. Anthropology of Food (S7): 1-20.

Jauho M, Makela J and Niva M (2016) Demarcating social practices: The case of weight management. Sociological Research Online 21(2): 1.1-5.6.

Keller M, Halkier B and Wilska T (2016) Policy and governance for sustainable consumption at the crossroads of theories and concepts. Environmental Policy and Governance 26(2): 75-88.

Kendall H, Brennan M, Seal C, Ladha C and Kuznesof S (2016) Behind the kitchen door: A novel mixed method approach for exploring the food provisioning practices of the older consumer. Food Quality and Preference 53: $105-116$.

Lahlou S (2011) How can we capture the subject's perspective? An evidence-based approach for the social scientist. Social Science Information/Information Sur Les Sciences Sociales 50(3-4): 607-655.

Lahlou S (2015) Subjective evidence based ethnography: Method and applications. Integrative Psychological \& Behavioral Science 49(2): 216-238.ho

Larsen J (2014) (Auto)Ethnography and cycling. International Journal of Social Research Methodology 17(1): $59-71$.

Mäkelä J (2009) Meals: the social perspective. In: Meiselman HL (ed) Meals in Science and Practice: Interdisciplinary Research and Business Applications. Cambridge: Woodhead Publishing, xxvi, $681 \mathrm{~s}$. 
Martens L and Scott S (2004) Domestic Kitchen Practices: Routines, Reflexivity and Risk. ESRC End of Award Report: 21-52.

Martens L (2012) Practice 'in talk' and talk 'as practice': Dish washing and the reach of language. Sociological Research Online 17(3): 1.1-5.5.

Martens L, Halkier B and Pink S (2014) Researching habits: advances in linguistic and embodied research practice INTRODUCTION. International Journal of Social Research Methodology 17(1): 1-9.

Martens L and Scott S (2017) Understanding Everyday Kitchen Life: Looking at performance, into performance and for practice. In: Jonas M, Littig B and Wroblewski A (eds) Methodological Reflection on Practice Oriented Theories. London: Springer, pp.177-191.

McCabe M and de Waal Malefyt T (2015) Creativity and cooking: Motherhood, agency and social change in everyday life. Journal of Consumer Culture 15(1): 48-65.

Meah A and Watson M (2011) Saints and Slackers: Challenging discourses about the decline of domestic cooking. Sociological Research Online 16(2): 1.1-5.4.

Meah A (2014) Reconceptualizing power and gendered subjectivities in domestic cooking spaces. Progress in Human Geography 38(5): 671-690.

Mills S, White M, Brown H, Wrieden W, Kwasnicka D, Halligean J, Robalino S and Adams J (2017) Health and social determinants and outcomes of home cooking: A systematic review of observational studies. Appetite 111: 116-134.

Neuman N (2016) Stories of masculinity, gender equality, and culinary progress: On foodwork, cooking, and men in Sweden. Uppsala University, Department of Food, Nutrition and Dietetics: Uppsala.

O'Connell R and Brannen J (2016) Food, Families and Work. London: Bloomsbury.

Pink S (2012a) Situating Everyday Life: Practices and Places. Los Angeles, CA: Sage.

Pink S (2012b) Advances in Visual Methodology. Los Angeles, CA: SAGE.

Pääkkönen H and Hanifi R (2011) Ajankäytön Muutokset 2000-Luvulla. Helsinki: Tilastokeskus.

Reckwitz A (2002) Toward a theory of social practices: A development in culturalist theorizing. European Journal of Social Theory 5(2): 243-263.

Schatzki TR (1996) Social Practices: A Wittgensteinian Approach to Human Activity and the Social. Cambridge: Cambridge University Press.

Schatzki TR (2001a) Practice mind-ed orders. In: Knorr-Cetina K, Savigny Ev and Schatzki TR (eds) The

Practice Turn in Contemporary Theory. London: Routledge, pp.50-63.

Schatzki TR (2001b) Introduction: practice theory. In: Knorr-Cetina K, Savigny Ev and Schatzki TR (eds) The

Practice Turn in Contemporary Theory. London: Routledge, pp.10-23.

Schatzki TR (2010) Materiality and social life. Nature \& Culture 5(2): 123-149.

Schatzki TR (2016) Practice theory as flat ontology. In: Spaargaren G, Weenik D and Lamers M (eds) Practice Theory and Research: Exploring the Dynamics of Social Life. NY: Routledge, pp.28-42.

Schatzki TR (2017) Sayings, texts and discursive formations. In: Hui A, Schatzki TR and Shove E (eds) The Nexus of Practices: Connections, Constellations, Practitioners. New York: Routledge, pp.126-140.

Short F (2006) Kitchen Secrets: The Meaning of Cooking in Everyday Life. New York, NY: Berg.

Shove E, Pantzar M and Watson M (2012) The Dynamics of Social Practice: Everyday Life and how it Changes. Los Angeles, CA: Sage. 
Spaargaren G, Weenik D and Lamers M (2016) Introduction: Using practice theory to research social life. In: Spaargaren G, Weenik D and Lamers M (eds) Practice Theory and Research: Exploring the Dynamics of Social Life. NY: Routledge, pp.3-27.

Sutton D (2006) Cooking skill, the senses, and memory: The fate of practical knowledge. In: Edwards E, Gosden C and Phillips RB (eds) Sensible Objects: Colonialism, Museums and Material Culture. Oxford: Berg, pp.87118.

Truninger M (2011) Cooking with Bimby in a moment of recruitment: Exploring conventions and practice perspectives. Journal of Consumer Culture 11(1): 37-59.

Warde A (2005) Consumption and theories of practice. Journal of Consumer Culture 5(2): 131-153.

Warde A (2016) The Practice of Eating. Cambridge: Polity.

Watson M (2017) Placing power in practice theory. In: Hui A, Schatzki TR and Shove E (eds) The Nexus of Practices: Connections, Constellations, Practitioners. New York: Routledge, pp.169-182.

Weenik D and Spaargaren G (2016) Emotional agency navigates a world of practices. In: Spaargaren G, Weenik D and Lamers M (eds) Practice Theory and Research: Exploring the Dynamics of Social Life. New York, NY: Routledge, pp.60-84.

Welch D and Warde A (2017) How should we understand 'general understandings'? In: Hui A, Schatzki TR and Shove E (eds) The Nexus of Practices: Connections, Constellations, Practitioners. New York: Routledge, pp.183-196.

Wills WJ, Meah A, Dickinson AM and Short F (2013) Domestic Kitchen Practices: Findings from the 'Kitchen Life' Study. University of Hertfordshire: Foods Standards Agency.

Wills WJ, Dickinson AM, Meah A and Short F (2016) Reflections on the use of visual methods in a qualitative study of domestic kitchen practices. Sociology 50(3): 470-485.

Wolfson JA, Bleich SN, Smith KC and Frattaroli S (2016) What does cooking mean to you?: Perceptions of cooking and factors related to cooking behavior. Appetite 97: 146-154. 